\title{
A case report of life threatening Dapsone Hypersensitivity Syndrome
}

\author{
Santoshkumar R. Jeevangi*, Amreen Saba
}

Department of Pharmacology, M.R. Medical College, Gulbarga, Karnataka, India

Received: 14 December 2016 Accepted: 04 January 2017

\section{*Correspondence to:}

Dr. Santoshkumar R. Jeevangi, Email: djeevangi@gmail.com

Copyright: (C) the author(s), publisher and licensee Medip Academy. This is an openaccess article distributed under the terms of the Creative Commons Attribution NonCommercial License, which permits unrestricted noncommercial use, distribution, and reproduction in any medium, provided the original work is properly cited.

\begin{abstract}
Dapsone is widely used for a variety of infections, immune and hypersensitivity disorders. However, the use of Dapsone may be associated with a plethora of adverse effects, the most serious being Dapsone Hypersensitivity Syndrome (DHS) wherein the patient typically presents with a triad of fever, skin eruption and internal organ involvement, that occurs during first 2 to 8 weeks of initiating the treatment. The incidence of DHS ranges from $0.5 \%$ to $3 \%$. Here we report a case of severe life threatening Dapsone induced hypersensitivity reaction in a 21year old female who presented with high grade fever, generalized lymphadenopathy, skin rash and hepato-splenomegaly. This condition is best approached with immediate discontinuation of offending drug and prompt administration of oral or IV glucocorticoids. The case is being reported to emphasize the need for timely diagnosis and prompt treatment for successful outcome as it can cause irreversible organ damage or death if untreated early.
\end{abstract}

Keywords: Dapsone, Dapsone Hypersensitivity Syndrome (DHS), Hansen disease

\section{INTRODUCTION}

Dapsone has been the drug of choice for the treatment of Leprosy (Hansen's disease) but it is also used for the treatment of many dermatologic conditions like dermatitis herpetiformis, vesicobullous dermatoses, cutaneous vasculitis, poly arteritis nodosa, nodulocystic acne and cutaneous mycetoma. ${ }^{1}$ It has antibiotic and antiinflammatory property that makes it suitable drug of choice for the above mentioned conditions. ${ }^{2}$ Dapsone has been increasingly utilized in the chemoprophylaxis of pneumocystis carini infection in combination with trimethoprim/sulfamethoxazole in HIV patients. This has led to increasing incidence of dapsone related complications. One among the various adverse effects includes DHS. This case report emphasizes effects associated with DHS and the discussion provides an overview of pathogenesis, clinical feature, diagnosis and management of DHS.

\section{CASE REPORT}

A 21 year young unmarried female with average built admitted to Basweshwara hospital Gulbarga with presenting complaints of fever, rashes all over the body and difficulty in swallowing. History revealed that she was diagnosed with borderline leprosy by a dermatologist, for which she was given tablet dapsone, tablet clofazimine and tablet rifampicin. Patient continued the treatment for 45 days before she could present with the above complaints. Detailed personal history and family history was taken. She was nonalcoholic and a non-smoker, no history of allergy to dapsone or any other drugs.

\section{Various investigations}

$\mathrm{Hb}-10.8 \mathrm{~g} \%$, Total WBC-10,200 cells/cumm and differential count PMN-78\%, L-18\%, E-04\%, M-0, B-0, 
ESR-20mm/1sthr, blood urea-34mg/dl, serum creatinine$1.0 \mathrm{mg} / \mathrm{dl}$, bilirubin-total- $2.7 \mathrm{mg} / \mathrm{dl}$ and direct- $0.9 \mathrm{mg} / \mathrm{dl}$, AST-115U/L, ALT-298U/L, renal function test and urine analysis were normal, chest radiography and abdominal sonography were unremarkable, blood sugar was in normal limit. Peripheral smear for malarial parasite, Widal test and HIV test were negative.

On dermatological examination, there was extensive skin involvement with redness, necrosis, and red-purple maculopapular rashes. Painful crusts and erosions were noted on mucosa along with generalized lymphadenopathy, hepato-splenomegaly and raised temperature. On oral cavity examination, there were multiple ulcers with erythematous border, ulceration in the angle of mouth and mucosal surface of lips and tongue.

The patient was treated symptomatically with injection hydrocortisone $100 \mathrm{mg}$ I.V. 6 hourly daily, tablet cetrizine $10 \mathrm{mg}$ OD, tablet dimethindene maleate, injection crystalline penicillin 20 lac units 6 hourly, I.V. DNS and I.V 5\% Dextrose, injection ranitidine 1 ampoule IV BD, oxygen inhalation and tablet paracetamol 500mg TID and was discharged after 5 days of hospitalization when laboratory studies revealed normal reports.

The clinical features with which the patient presented were similar to those seen in a typical case of DHS. Conditions like herpes simplex, blistering skin diseases (e.g. pemphigus vulgaris and bullous pemphigoid), mucocutaneous diseases (e.g. Behcet disease and Reiter's syndrome) and vasculitides (e.g. systemic lupus erythematoses and polyarteritis nodosa) were excluded clinically.

Thus, we conclude that this is the case of dapsone induced hypersensitivity syndrome and the patient recovered after stopping dapsone. Further re-challenging with oral dapsone was not done in the interest of the patient and due to ethical constraints.

\section{DISCUSSION}

Dapsone is a 4, 4'-Diaminodiphenylsulphone synthesized in 1908, but its antibacterial properties were discovered in 1937. Dapsone has been used as a first-line treatment for leprosy since 1950s. It is chemically related to sulfonamides and has similar mechanism of action i.e. inhibition of PABA incorporation into folic acid. It is metabolized in two pathways, $\mathrm{N}$-acetylation and $\mathrm{N}$ hydroxylation (oxidation). The formation of toxic intermediate metabolites such as nitrosamines and possibly other compounds through N-hydroxylation pathway are thought to be responsible for the hemolytic anemia, methemoglobinemia and dapsone syndrome. ${ }^{3}$

However, the production and detoxification of toxic metabolites of dapsone is influenced by a number of genetic and environmental factors. ${ }^{4}$ Due to significant enterohepatic circulation of dapsone, it has a long elimination half-life averaging between 24- 30 hours. Strong protein binding of the drug itself (70-90\%) and its major metabolite monoacetyldapsone (99\%) contribute to that long half-life in body up to 35 days. ${ }^{5}$ An initial dose of $50 \mathrm{mg} /$ day is prescribed, followed by increase of $25 \mathrm{mg} /$ day at weekly intervals, titrated to the minimal dosage necessary for the effect, always with appropriate lab testings. ${ }^{6}$ The side effects of dapsone are less if plasma concentration is below $5 \mathrm{mg} / \mathrm{L}$.

DHS is a rare, potentially fatal idiosyncratic systemic hypersensitivity syndrome characterized by fever, skin rash, eosinophilia, lymphadenopathy, hepatic, pulmonary and other systemic manifestations that can lead to irreversible organ damage or even death if not recognized early and managed properly. ${ }^{7}$ It can develop several weeks to as long as 6 months after the treatment initiation and the reported incidence range $0.5-3 \% .^{8}$ Anaemia, oral erosions, conjunctivitis, splenomegaly, atypical lymphocytosis and rise of liver enzymes are the other corroborative findings. All these features need not necessarily be present.

Probenecid reduces renal excretion of dapsone, increases its serum concentration leading to adverse effects. rifampicin reduces serum concentrations of dapsone to a level that may compromise efficacy in infections other than leprosy. Dapsone may reduce the anti-inflammatory effects of clofazimine. ${ }^{9}$

Drugs most frequently causing hypersensitivity syndrome include anticonvulsants- phenytoin sodium, carbamazepine, sulphonamide antibiotics and sulfones. ${ }^{4}$ Leta et al performed a systematic review of the diagnostic criteria for DHS (33 papers, $\mathrm{N}=105$ cases, 1956-2001), showing that $59 \%$ of these 105 cases could be classified as complete DHS forms (fever, rash, lymphadenopathy and hepatitis). This study also revealed that most of the patients with complete DHS forms presented leprosy (90\%) were classified as paucibacillary $(71 \%) .{ }^{10}$

The main treatment for DHS is immediate discontinuation of the drug with initiation of oral or parenteral glucocorticoids, depending on severity. Dapsone is found to persist in the body for up to 35 days hence glucocorticoids should be tapered gradually over a period of more than one month. Supportive measures like nutritional support, meticulous fluid and electrolyte balance, control and prevention of infectious complications (cellulitis, sepsis) and skin care if necrotizing disease.

In some patients, in spite of drug withdrawal and steroid therapy, a relapsing and chronic course might ensue. A high index of suspicion is needed for early diagnosis and prompt treatment of these kind of adverse reactions by drugs. According to Naranjo ADR probability scale, score is 7 and this case is a probable ADR, and as per WHO- 
UMC (Uppsala Monitoring Centre) causality assessment system, it fits in Probable/ Likely ADR. ${ }^{11,12}$

\section{CONCLUSION}

In conclusion, Physicians mainly in geographical areas with high prevalence rates of leprosy should be aware of this potentially fatal and probably not so rare hypersensitivity reaction to dapsone.

Funding: No funding sources Conflict of interest: None declared

Ethical approval: Not required

\section{REFERENCES}

1. Zhu YI, Stiller MJ. Dapsone and sulfones in dermatology: overview and update. J Am Acad Dermatol. 2001;45:420-34.

2. Volcheck GW. Clinical evaluation and management of drug hypersensitivity. Immunol Allergy Clin North Am. 2004;24:357-71.

3. Grossman SJ, Jollow DJ. Role of dapsone hydroxylamine in dapsone induced hemolytic anaemia. J Pharmacol Exp Ther. 1998;244(1):118-25.

4. Prussik R, Shear NH. Dapsone hypersensitivity syndrome. J Am Acad Dermatol. 1996;35(2 pt 2):346-9.

5. Zuidema J, Hilbers-Modderman ESM, Merkus FWHM. Clinical pharmacokinetics of dapsone. Clin Pharmacokinet. 1986;11(4):299-315.
6. Burkhart C, Morrell D, Goldsmith L. Dermatological Pharmacology:Brunton LB, Chabner BA, Knollmann BC. Goodman and Gilman's The Pharmacological Basis of Therapeutics. 12th ed. New York, NY: McGraw-Hill; 2011:1824.

7. Kosseifi SG, Guha B, Nassour DN, Chi DS, Krishnaswamy G. The dapsone hypersensitivity syndrome revisited: A potentially fatal multisystem disorder with prominent hepatopulmonary manifestations. J Occup Med Toxicol. 2006;1:9.

8. Leslie KS, Gaffney K, Ross CN, Ridley S, Barker $\mathrm{TH}$, Garioch JJ. A near fatal case of the dapsone hypersensitivity syndrome in a patient with urticarial vasculitis. Clin Exp Dermatol. 2003;28(5):496-8.

9. Sweetman SC, Blake SP. Antibacterials. In: Martindale The Complete Drug Reference, 36th ed. Pharmaceutical Press. 2009:261.

10. Leta GC. Simas MEPAS, Oliveira MLW, Gomes MK. Síndrome de hipersensibilidade à dapsona: revisãosistemática dos critériosdiagnósticos. Hansen Int. 2003;28(1):79-84.

11. Naranjo CA, Busto U, Sellers EM, Sandor P, Ruiz I, Roberts EA, et al. A method for estimating the probability of adverse drug reactions. Clin Pharmacol Ther. 1981;30(2):239-45.

12. The use of WHO-UMC system for standardized case causality assessment. http://www.WHO-UMC.org/ graphics/4409.pdf.

Cite this article as: Jeevangi SR, Saba A. A case report of life threatening Dapsone Hypersensitivity Syndrome. Int J Basic Clin Pharmacol. 2017;6:471-3. 